\title{
Upaya Peningkatan Pengetahuan dan Keterampilan Remaja Untuk Deteksi Dini Kanker Payudara Melalui Pemeriksaan Payudara Sendiri (SADARI)
}

\author{
Nikmatul Khayati1 ${ }^{1}$ Sri Rejeki ${ }^{1}$, Machmudah Machmudah¹, Pawestri Pawestri1, Yunie \\ Armiyati' ${ }^{1}$ Roni Sianturi1
}

1 Fakultas Ilmu Keperawatan dan Kesehatan, Universitas Muhammadiyah Semarang, Indonesia

\section{Informasi Artikel}

Riwayat Artikel:

- Submit 13 Mei 2021

- Diterima 8 Juni 2021

- Diterbitkan 10 Juni 2021

Kata kunci:

Pengetahuan; Kanker

Payudara; ketrampilan SADARI

\begin{abstract}
Abstrak
Masa remaja merupakan awal masa pubertas yang ditandai dengan tumbuh dan berkembangnya hormon-hormon pubertas secara cepat. Pesatnya pertumbuhan tanda seks sekunder seperti pembesaran sel di payudara dapat menjadi faktor risiko terjadinya kanker payudara. Kanker payudara merupakan kanker terbesar pada perempuan yang terjadi pada usia subur sekitar 42,1 per 100.000 penduduk. Perlu upaya deteksi dini yang dapat dilakukan dengan Pemeriksaan payudara sendiri (SADARI). SADARI atau Breast Self Examination (BSE) adalah metode sistematik untuk pemeriksaan adanya kelainan pada daerah dada terutama payudara sampai area ketiak dengan cara melihat/inspeksi dan meraba/palpasi yang dilakukan secara mandiri. SADARI merupakan tindakan yang aman, murah, sederhana dan efektif digunakan untuk deteksi dini Kanker Payudara. Tujuan utama kegiatan pengabdian masyarakat ini untuk meningkatkan pengetahuan dan skill remaja tentang SADARI. Tujuan khususnya untuk meningkatkan pengetahuan tentang kanker payudara, faktor risiko, tanda dan gejala, upaya pencegahan, kanker payudara, waktu yang efektif untuk SADARI dan dapat melakukan praktik SADARI. Metode yang dilakukan berupa ceramah, diskusi, demonstrasi, dan redemonstrasi. Persiapan dilakukan bersama tim untuk pembagian tanggung jawab kegiatan dan persiapan media. Sebelum dan sesudah kegiatan dilakukan evaluasi awal dan akhir terkait materi. Mayoritas 75\% peserta berpengetahuan cukup untuk konsep kanker payudara dan 90\% kategori kurang untuk skill SADARI. Setelah dilaksanakan kegiatan edukasi terjadi peningkatan pengetahuan dalam kategori baik sebesar 95\% dan 90\% memiliki ketrampilan dalam kategori baik untuk SADARI. Kegiatan ini perlu disebarluaskan dan ditingkatkan motivasinya agar perempuan memiliki kesadaran untuk rutin melakukan SADARI agar dapat mendeteksi kanker payudara secara dini.
\end{abstract}

\section{PENDAHULUAN}

Adanya perubahan gaya dan pola hidup dimasyarakat terutama perubahan pola makan yang serba praktis (junk food), mengandung banyak pengawet, pewarna, dan zat berbahaya lainnya akan memberikan efek negative pada tubuh. Salah satu dampak negative tersebut adalah semakin banyaknya ditemukan kanker di masyarakat seperti kanker payudara akibat pembelahan dan pertumbuhan sel 
abnormal yang terjadi secara cepat di payudara (Oemiyati, R, 2011).

Penyebab pasti kanker payudara belum diketahui, tetapi akan meningkat pada perempuan yang mempunyai faktor risiko seperti keturunan cancer, obesitas, banyak terpapar banyaknya zat polutan dari lingkungan sekitar, terpapar zat-zat kardiogenik, maka akan mempercepat (Suyatno \& Emir, 2014).

Angka kejadian kanker payudara merupakan kanker terbanyak pada perempuan sebesar 42,1 per 100.000 penduduk dengan rata-rata kematian 17 per 100.000 penduduk. Prevalensi ini meningkat dari 1,4 per 1000 penduduk pada tahun 2013 menjadi 1,79 per 1000 penduduk pada tahun 2018 (Riskesdas, 2018). Prevalensi tertinggi di DI Yogyakarta sebesar 4,86 per 1000 penduduk. Kanker payudara di Asia sebesar 674 dapat menyerang usia remaja sampai dewasa.

Pada masa remaja terjadi pertumbuhan hormon pubertas sebagai tanda awal aktifnya organ reproduksi. Adanya tanda seks sekunder berupa pertumbuhan sel payudara yang semakin aktif dan cepat membesar yang baik laki-laki maupun perempuan. Pembesaran payudara terutama pada perempuan ini harus disikapi dengan baik melalui perawatan secara rutin dan sehat. Percepatan pertumbuhan sel ini merupakan salah satu pemicu kanker payudara (WHO, 2014).

Upaya deteksi dini pada kanker payudara melalui pemeriksaan payudara sendiri/SADARI (Saryono, 2009). SADARI merupakan pengamatan payudara bagian depan, sisi kanan dan kiri terkait bentuk dan kesimetrisan, perubahan warna pada kulit sekitar payudara, bentuk tampilan putting, areola, pengeluaran cairan abnormal, darah, atau nanah dengan bau khas busuk. SADARI dapat dilakukan sendiri tanpa harus datang ke petugas kesehatan (Olfah, 2013). Kegiatan ini juga didukung oleh pemerintah melalui program pemeriksaan payudara Klinis (SADANIS) (Riskesdas, 2018).

Pengetahuan dan ketrampilan serta praktik SADARI masih rendah (Kemenkes RI (2015), Thaha (2017)), yang dibuktikan dengan sebagian besar kasus kanker payudara yang berobat ke RS atau dokter sudah dalam keadaan stadium lanjut $(>50 \%)$. Oleh karena itu, upaya preventive dan promotive perlu kita optimalkan melalui sosialisasi di masyarakat dengan edukasi/pendidikan Kesehatan sebagai upaya pencegahan yang cukup murah, aman, serta mudah dilakukan (Mulyani, 2013).

American Cancer Society (2013) menganjurkan remaja awal terutama wanita lebih dari 20 tahun sampai dewasa untuk melakukan screening dengan SADARI secara rutin setiap bulannya pada hari ke 7 sampai 10 pasca menstruasi, walaupun tidak ada keluhan atau gejala (Mulyani, 2013). Deteksi Dini melalui Skreening SADARI ini mampu menurunkan 25\%-30\% angka kematian akibat kanker payudara (American Cancer Society, 2013), peningkatan kesadaran dan pengobatan (Widodo, 2014).

Upaya lain sebagai tindakan promotive dengan pemilihan bahan Bra yang menyerap keringat, nyaman, tidak terlalu ketat, tidak menggunakan kawat penyangga dan busa yang keras. Hal ini dapat memicu terjadinya gangguan aliran darah, perfusi oksigen ke payudara. Akibat hambatan ini maka seseorang berisiko terjadi sumbatan aliran darah, benjolan/tumor dan berkembang menjadi kanker payudara jika tidak segera dilakukan upaya-upaya pencegahan.

Kurangnya pengetahuan, ketrampilan dan rendahnya kesadaran untuk melakukan SADARI menjadikan kasus ini terjadi 
peningkatan setiap tahunnya dan diketahui dalam kondisi sudah parah bahkan metastase/menyebar ke organ sekitarnya. Berdasarkan fenomena yang berhubungan dengan banyaknya kasus keganasan berupa kanker payudara akibat terlambatnya deteksi dini kasus tersebut, maka penulis menyadari akan pentingnya sosialisasi upaya-upaya preventive dan promotive agar prognosis lebih baik (Thaha, 2017).

\section{METODE}

Kegiatan pengabdian masyarakat ini dilaksanakan melalui pelibatan secara aktif pada remaja yang tergabung dalam kelompok remaja untuk diberikan edukasi dan latihan ketrampilan deteksi dini kanker payudara. Pemilihan metode pada kegiatan pengabdian masyarakat ini yaitu Ceramah, Tanya Jawab/diskusi, Case study, dan Skill Practice.

Peserta terdiri dari remaja putra dan putri. Penyampaian materi melalui media zoom meeting selama 150 menit. Media lain yang digunakan berupa Laptop beserta perangkat pendukungnya, bahan/materi tentang konsep dasar kanker Payudara, upaya pencegahan, dan deteksi dini melalui pemeriksaan payudara sendiri (SADARI), dan Video pelaksanaan pemeriksaaan SADARI.

Adapun tahapan proses pelaksanaan kegiatan pengabdian masyarakat, sebagai berikut:

\section{Tahap persiapan}

1). Persiapan awal dengan koordinasi tim pelaksana untuk membahas strategi dan pembagian tugas; 2). Petugas berkoordinasi dengan perwakilan remaja dan pelajar di SMA Semarang untuk menyampaikan maksud, tujuan, dan rencana kegiatan; 3). Mengadakan kesepakatan bersama setelah terkumpul 20 peserta; 4). Membuat Whatapp group untuk koordinasi; 5).
Setelah penjelasan awal bersama perwakilan kelompok, maka tercapai kesepakatan pelaksanaan kegiatan untuk waktu, tempat, jam, dan materi pengabdian masyarakat.

Kegiatan dilaksanakan melalui media zoom meeting, link dibagikan 1 jam sebelum acara dimulai. Materi berupa power point, video teknik pelaksanaan SADARI. Persiapan dilakukan 30 menit sebelum acara dimulai dengan melakukan pengecekan yang terkait kepatenan dan stabilitas media audio visual (laptop dan jaringan koneksinya). Setelah media dapat berfungsi dengan baik, dapat di share screen maka kami simpan dengan baik dan siap digunakan.

\section{Tahap pelaksanaan}

Tahap awal pelaksanaan kegiatan ini, kita mulai dengan membagikan link zoom meeting dan dilanjutkan pembukaan oleh moderator. Pengabdian masyarakat ini dilakukan dengan tetap mematuhi protokol yaitu tidak berkerumun, berkumpul dalam satu tempat dan jaga jarak karena masih dalam situasi Pandemi Covid-19. Acara kedua yaitu penyampaian materi tentang konsep dasar kanker payudara, upaya pencegahan, dan cara deteksi dini melalui SADARI. Selanjutnya pemutaran Video SADARI dan dilanjutkan dengan sesi tanya jawab.

\section{Tahap Evaluasi}

Evaluasi jalannya kegiatan meliputi 3 unsur yaitu evaluasi struktur, proses, dan hasil.

Pada evaluasi struktur, seluruh perangkat dapat digunakan dan diterima dengan baik antar pemateri dan peserta. Kejernihan suara pemateri, tampilan power point dan pemutaran video tanpa ada hambatan. Evaluasi Proses meliputi jalannya rangkaian kegiatan pengabdian masyarakat dari awal hingga akhir. Evaluasi hasil dilakukan dengan 2 cara yaitu dengan 
mengajukan pertanyaan secara lisan dan tertulis di google form pada peserta terkait materi yang telah disampaikan, dan meminta peserta untuk melakukan redemonstrasi SADARI.

\section{HASIL DAN PEMBAHASAN}

Kegiatan pengabdian pada masyarakat telah dilaksanakan pada hari Jumat, tanggal 25 Juni tahun 2021, selama 120 menit. Kegiatan berupa pemberian edukasi tentang konsep dasar kanker payudara dan cara deteksi dini melalui ketrampilan pemeriksaan payudara sendiri (SADARI). Kegiatan dilakukan melalui metode daring dengan media zoom meeting.

Acara dihadiri oleh 20 remaja pelajar SMA 1 dalam keadaan sehat, dari lokasi rumah masing-masing.

Rangkaian kegiatan Edukasi diawali dengan validasi dan Brain Storming tentang gambaran kondisi perubahan pola hidup saat ini, kasus-kasus keganasan terutama yang berhubungan dengan keganasan pada system reproduksi. Sebagian besar peserta (70\%) dapat menyebutkan perubahan gaya dan pola hidup yang saat ini menjadi trend yaitu konsumsi makanan serba cepat saji, junkfood, banyak mengandung pengawet, pewarna, dan pemanis. $70 \%$ peserta dapat menyebutkan macam-macam kanker. Sebagian besar responden memiliki tingkat pengetahuan cukup baik atau sedang. Hal ini sesuai dengan latar belakang Pendidikan peserta sebagai pelajar SMU, menguasai iptek sehingga dapat mencari informasi dari televisi, internet, atau media sosial lainnya. Seseorang berpendidikan tinggi lebih mudah menerima informasi sehingga memiliki pengetahuan lebih luas daripada Pendidikan rendah.

Terdapat $30 \%$ peserta mampu menyebutkan jenis kanker yang mengenai sistem reproduksi, dan $90 \%$ peserta dapat belum tahu bagaimana cara deteksi dini adanya kanker payudara dengan cara yang bisa dilakukan sendiri dirumah. Kemampuan peserta dalam katogori kurang terkait pengetahuan tentang kanker system reproduksi dan ketrampilan untuk deteksi dini kanker payudara. Hal ini terjadi akibat berbagai faktor, salah satunya adalah pengalaman, usia, dan tingkat pendidikan peserta masih SMU bukan jurusan Kesehatan sehingga lebih sedikit mendapatkan akses informasi SADARI (Alvariariza, 2020).

Acara kedua yaitu memberikan penjelasan tentang definisi kanker payudara, penyebab dan factor risiko, tanda gejala dan manifestasi klinik, komplikasi, penatalaksanaan therapi, dan upaya antisipasi serta cara skrening dengan pemeriksaan payudara sendiri (SADARI). Materi yang kedua berhubungan dengan pemeriksaan payudara sendiri (SADARI), meliputi definisi, tujuan dan manfaatnya, waktu pelaksanaan, rangkaian langkahlangkah pemeriksaan sadari.

Selama pemaparan materi, peserta tampak antusias dan mengikuti jalannya edukasi dengan penuh perhatian, mengikuti secara seksama dari awal sampai akhir tanpa ada yang leave dari zoom meeting. Setelah pemaparan materi, peserta diberikan kesempatan untuk bertanya terkait konsep dasar kanker payudara, antisipasi, dan upaya deteksi dini, konsep SADARI, tujuan, manfaat, dan waktu pelaksanaan.

Ada 10 peserta (50\%) juga aktif bertanya kepada narasumber setelah diberi kesempatan. Peserta menyatakan senang dan puas dengan jawaban pemateri. Selanjutnya pemateri memberikan 5 pertanyaan terkait konsep kanker payudara dan upaya menghidarinya dan cara deteksi dini kanker payudara. Hasilnya sebagian besar peserta $95 \%$ peserta dapat menjawab dengan benar. Hal ini terjadi memiliki konsentrasi yang baik selama proses edukasi sehingga pengetahuan meningkat. 
Pengetahuan merupakan domain untuk membentuk tindakan seseorang (overt behavior) yang berasal dari pengalaman, penelitian. Perilaku yang didasari oleh pengetahuan akan lebih langgeng daripada perilaku yang tidak didasari oleh pengetahuan (Notoatmodjo, 2012). Selain itu, perilaku masyarakat tentang status Kesehatan dipengaruhi pula oleh sikap, kepercayaan, dan tradisi.

Setelah pemaparan materi, selanjutnya diputarkan video langkah-langkah SADARI. Peserta diberikan kesempatan untuk redemonstrasi secara bersama-sama. Hasilnya Sebagian besar 90\% dapat melakukan praktik SADARI dengan tepat.

Materi dan ketrampilan SADARI ini mudah diterima oleh peserta karena 1) semua peserta adalah remaja terpelajar yang sedang duduk di bangku SMU; 2) media diberikan secara sederhana sehingga mudah dibaca, difahami; dan 3) ditambah dengan adnya gambar-gambar visualisasi serta video yang memperjelas skill teknik SADARI.

Suasana edukasi dirancang dengan santai sehingga peserta nyaman mengikuti tanpa ada perasaan tertekan atau ketakutan.

Acara diakhiri dengan penyimpulan materi dan memberikan saran terhadap peserta untuk rutin melakukan SADARI terutama pasca mentruasi hari ke 7-10 dan menyebarluaskan informasi kepada masyarakat sekitar.

\section{SIMPULAN}

Terdapat peningkatan pengetahuan tentang kanker yang sering terjadi pada sistem reproduksi dari 30\% menjadi 90\% setelah edukasi. Terjadi peningkatan ketrampilan SADARI sebesar 90\%. Upaya preventive dan promotif melalui skrening dengan SADARI perlu disosialisasikan dan disupport sebagai upaya pemberian dukungan kepada
Pemerintah dalam rangka mewujudkan derajat kesehatan masyarakat yang tinggi, menurunkan angka kesakitan/mortalitas; maka perlu dilakukan edukasi kesehatan, pelatihan ketrampilan SADARI sehingga pengetahuan dan ketrampilan masyarakat meningkat secara mandiri sehingga meringankan tugas tenaga kesehatan dan Pemerintah.
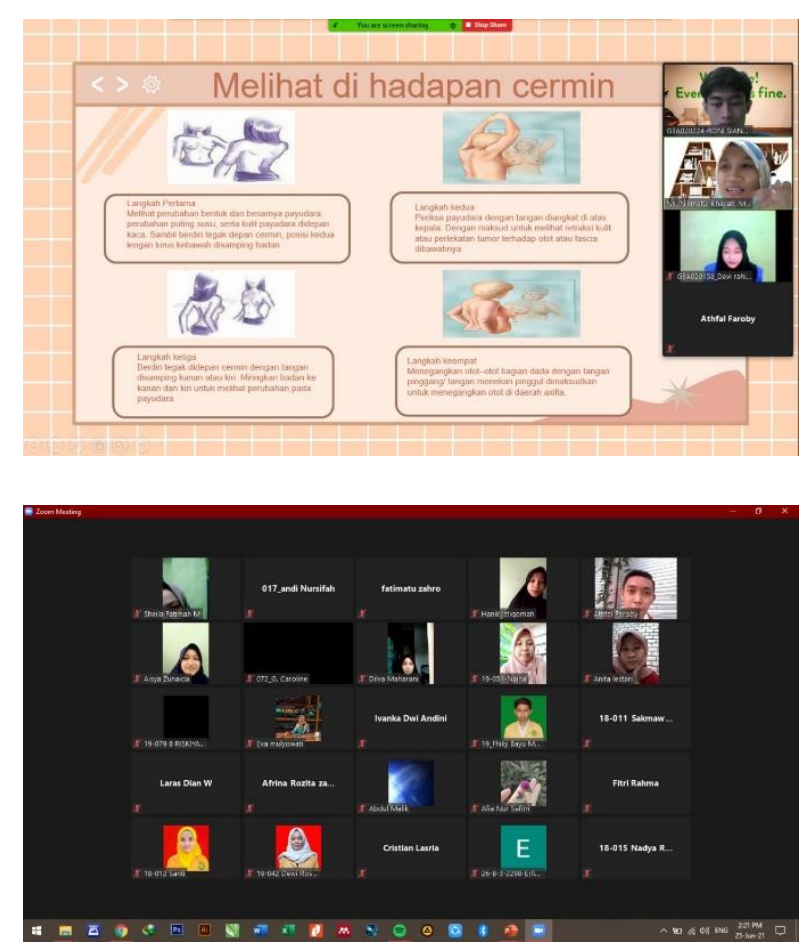

Gambar 1

Pelaksanaan pengabdian masyarakat menggunakan zoom meeting

\section{UCAPAN TERIMA KASIH}

Penulis mengucapkan terimakasih kepada semua tim dan pihak terkait yang telah mendukung jalannya kegiatan pengabdian masyarakat ini.

\section{REFERENSI}

Alvariariza, A., Adiputra, P.A.T. (2020). Gambaran tingkat pengetahuan tentang periksa payudara sendiri (SADARI) pada mahasiswa Fakultas Kedokteran Universitas Udayana, Bali, Indonesia Angkatan 2013-2015. Intisari sain Medis.11 (1): 190-193 
Estrada, S.S., Review of the New American Cancer Society Guidelines for Breast Cancer Screening for Women at Average Risk. J Adv Pract Oncol. 2016; 7 (5): 563-566

Jhons Hopkins. (2020). Breast Exam. Retrieved June 23, 2021, from https://www.hopkinsmedicine.org/kimmel_ca ncer_center/cancers_we_treat/breast_cancer_p rogram/treatment_and_services/risk_and_prev ention/breast_exam.html

Kementerian Kesehatan Republik Indonesia. (2018). Pusat Data dan Informasi Kementerian Kesehatan RI. www.depkes.go.id

Mulyani \& Nuryani (2013). Kanker Payudara dan PMS pada Kehamilan. Yogyakarta: Nuha Medika

Notoatmodjo, S. (2012). Promosi Kesehatan dan Perilaku Kesehatan. Jakarta: Rhineka Cipta

Oemari R, Rahajeng E, Kristanto AY. Prevalensi Tumor dan Beberapa factor yang mempengaruhinya di Indonesia. Buletin Penelitian Kesehatan. 2011;39 (4):190-204

Olfah, M \& Badi'ah. (2013). Kanker payudara dan SADARI. Yogyakarta: Nuha Medika
Saryono \& Roischa, D.P. (2009). Perawatan Payudara dilengkapi dengan deteksi dini terhadap penyakit kanker payudara. Yogyakarta: Numet

Suyatno \& Emir, T.P. (2014). Bedah Onkologi, diagnostic dan therapi. Jakarta: Sagung Seto

Thaha, R \& Widajadnja, N. (2017). Hubungan tingkat pengetahuan tentang kanker payudara dan perilaku pemeriksaan payudara sendiri (SADARI) pada Wanita usia 20-45 tahun di desa Sidera, Kecamatan Sigi Bimomaru. Jurnal Kesehatan Tadulako. 3 (2), 40-46.

Widodo, I., Dwianingsih, E.K., Triningsih E, Utoro, T., Soeripto. Clinocophatological features of Indonesian breast cancers with different molecular subtypes. Asian Pac J cancers prev. 2014;15 (15):563-566

Word Health Organization. (2018). Breast Cancer: prevention and control. Diakses dari https://who.int

Yayasan Kanker Payudara Indonesia (2017). Periksa payudara sendiri (Sadari). Diperoleh dari http://pitapink-ykpi.or.id/sadari-periksapayudara-sendiri 